A major purpose or the I ecnncal Information Center is to provide the broadest dissemination possible of information contained in DOE's Research and Development Reports to business, industry, the academic community, and federal, state and local governments.

Although a small portion of this report is not reproducible, it is being made available to expedite the availability of information on the research discussed herein. 
LA-UR-84-2598

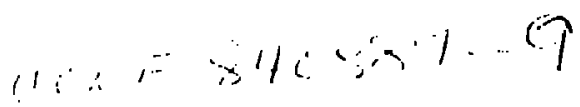

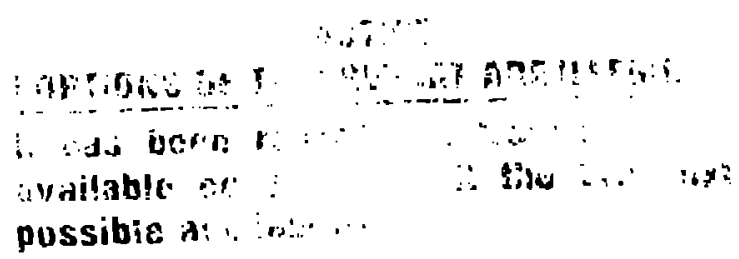

$$
\begin{aligned}
& \text { ha } \triangle-U: ?--\because 2-2500 \\
& \text { !n: }
\end{aligned}
$$

TITLE: Characterization of Electronis Stieak Tubes Including One With Internal CCD Readout

AUthor(S): P.B. Weiss, P. Black, H. Uona, L. Sprouse

SUBMITTED TO: Soclety of Photo 0ptical Instrumentation Engineers Loth lntermatlonal Illgh speed Photography and Photonl is, Strasbourg, firance, Nugust :7-11, 1984.

\title{
DISC'I.AIMKR
}

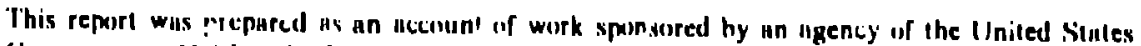
firvernment. Neither the I/nited Situtes (ioverninum nor uny agency thereuf, nor any of their

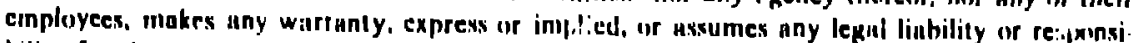

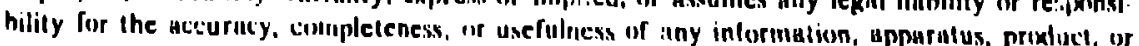
precis.s disclessed, or represents that its use would not infringe privhtely owned rights. Relerence herein :o any specific commercial prewluct, proxess, or service by Irade namle, ltudrmurk, munufucturer, or otherwise dices not necessurily cunstitute or imply its endorsenient, lecoms mendation, of favoring hy the United States (ienveriment or any agency theicol. The views and opinions ol suthers expressed herein do not necessarily slate or reflect thiose of the United Stutes (iovernment or uny ugency thereol.
\end{abstract}

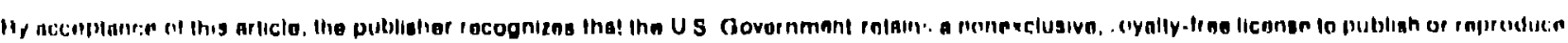

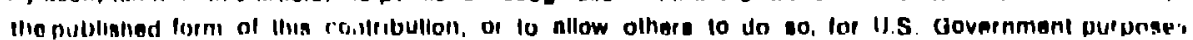

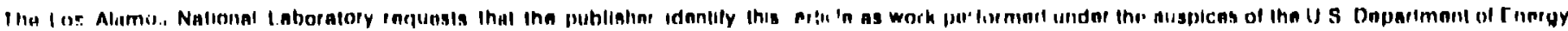

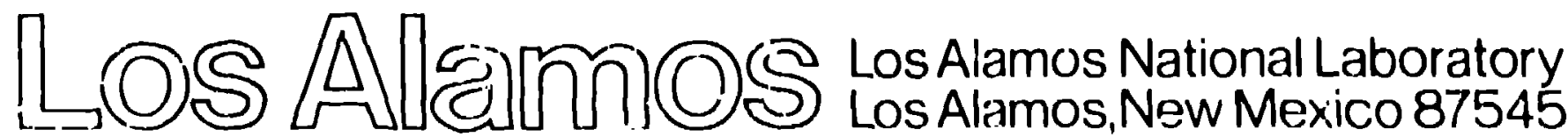


Characterization of electronic otreak tubes including one with internal CCD readout

P. B. Weiss, F. Black," H. Oona," and L. Sprouse

Physics Division, Los Alamos National Laboratory

P. O. Box 1663, Los Alarios, NM 87545

\begin{abstract}
Measuring techniques for characterizing electronic streak tubes including dynamic range and resolution are described. A particular tube with a CCD imaging device within ihe envelop is described.
\end{abstract}

\title{
Introduction
}

The streak tube 18 becoming of increasing importance in wany experimental applications as the experiments can be more quantitative with the device. The posslbilities of replacing banks of oscilloscopes for multiple bigna! recording, to recording many independent flbreaptic channels directly. to tomographic time analysis of a two dimensional eveni have all lead to increased Interest in these devicea.

We are curcently involved in evaluating different streak tubes from several different manufacturers. In particular our concerns involve achieving more spatial resolution with good dynamic range coupled with large useable photocathodes. The highest tims resolution has not been at the forefront of ollr interest.

\section{Measuring technigues}

The following parameters are presently being measured on prototype atreak tubes: Dynamic Range, Ilnearity, Quantum efficlency over wavelength, Photocathode gain, Spatial resolution (static Dynamic). Temporal Regolution, and Extinction Ratio.

The measurement of Dynamic Range Linearity can be usually done simultaneously and refer to the transfer characteristics relating input optical power or intensity io that output at the phosphor. 1

A source of optical power, typicallv a flashlamp optoliner, lo used to focus an image of a pinhole of different bizes onto the photocathode. A series of neutral density filters permits different intensities in a well defined and calibrated fashion to bo input into the tube under tedt. If absolute optical power levels are required then insertion of a callbiated rbdiometer between the optical sourse and atreak tube lo necesinry. Stablilty of the optical bource and radiometer need to be verifled if the testing is expected to take any substantial time. Dynamic range 18 measured by relatiny the input and output intensities. The output intensity (power) measurement will depond nn the ceadout cystem used. SIT (Slilcon Intensifled Target vidicon) or ciu cameras are the aystems most commonly uscd for dynamic range measurements not requiring absolute power measurementis. This 18 accompliahed by digitizing a $f$ rame of video and performing the requiced anaiysis and asoclatinn of relative intensity levels on the computer and an Image processing syst.m. The input intensity lerels, if only relative, can be represerited in forms of the neutral density filters used for adjustiang the input intenglicy. In this manner the transfer cliaracteristics relating input to output ale quantitatively measured and earily related to determine the dynamic range and deviation from linearity. A

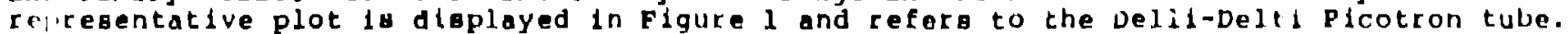
N.le that in this case, with the available equipment, 1 t was imposible to bring this tube lineo saturation and was "inent" over at leasta dynamic range of 100011.

Ship measurementa cf Quactum Efficlency photocathode Uniformity are most easily performed utilizing a colstant intenglty optical power oource. Generaliy thin is a Tunceten-Halogen lamp runnlng at $1 \mathrm{KW}$ Input prower. The opectal range (350-800 nm) $1 \mathrm{H}$ covergd sy alicrete t1jters, each of which has approximately 60 nm FWIM bandpas at the certer wavilength of each filter. A pinhole apertire is focused onto the photocathode. This image may vary in diameter and normally is not a factor alnce it is usually about loo iM thareby elimirating any question of overfiliting the photocathode or radiomeler drtector. Thls diameter also permits for eas mapping ot the uniformity of photocathode rupponse. 
The technique is to set up two separate configurations. The first involues biasing of the photcsathode to a sufficient potential ( $30 \mathrm{CV}$ ) 60 as the allow collection of all photoelectrons ejected bj the phutocathode. All electrodes and grounds (other than the photocathode) are connected together. The photoelectron current may be monitored either in the photocathode 1 ine or in the return consisting of all other electrodes. The photocurrent is measured with a high impedance picoameter. The second atep is to monitor the amount of optical power incident on the photucathode. An EGsG radiometer has been used and an overall 10-158 error $1 \mathrm{~s}$ assnciated with the guantum efficiency. By allowing for two orthogonal motions, this technique can be used to trace out the uniformity of the photocathode response. Figure $2 \mathrm{is} \mathrm{such}$ a map of response. The contour intervals are 108 intervals fur the picotron tube. Figure $31 \mathrm{la}$ a representative plot of quan-um afficiency at one particular point in the photocathode.

The determination of spatial resolution 15 a much more difficult problem. This 18 primarily due to the limiting resolution of readout system and the fact that the opatial resolution can be different along two orthogonal directions at the bime point.

The experimental configuration conststs of forming a well defined image of bome resolution target onto the photocathode. The resolution target uaed is usually a PRC-10 or preferably an Air Force test target when it 1 expected that the resolution w!ll bc

ifferent in different directions. The limiting resolution of the readout Bystem muet be known and understood in order to isolate the response of the streak tube alone. In practice, SIT or CCD system is optically (proximity) coupled to the nutput phosphor and the timing of the camera clock adjusted with respect to the system and sweep trigger so as to obtain a maximum aignal to nolse ratio. The projection of the resolution target is typically performed utilizing "optoliner" with either a D.C. or flashlamr assembly. The flashlamp assembly with the integrating diffuser is quoted as being iniform to 31 over the field available. Once proper optical and $t$ iming adjustmenis have been performed, the remaining procedure is stralght forward, involving digitization of a frame of lideo, transmitting it to the image processor and thereby computing the MTF for each set of resolution data. The digitization of a frame is accomplished with commercial hardware consisting of a LeCroy digitizer and memory an CAMAC link to a fiDp-ilsystem. Data is recorded in the aame fashion whether the measurement 18 in the "static" or the "streaked" mode. The sweep rate obviousiy needs to be recorded in concert with the particular frame of video. It ras become evident with some streak systems that the resolution can be a strong function of position on the phosphor. The previnusly quoted reter to the optimum or "best" resolution whether owept or not. Fnowledge ot the projected line pairs/mm is inferred by combining the measured magnificacion of the projection sysiem along with the known resolution target size. The accuracy of thlo determination is much better than the ercors involved in the rest of the system, und, is therefore assumed to 're exact. A plot of MTF vi spatial frequency is cisplayed in Figure 4. This again cepresents meaurements performed on the plcotron B atreak tube.

Temporal resolution as we attempt to measaure it $1 \mathrm{~s}$ a $m \cdot$ asuze of the lmpulse response of the bystem. A block diagram of the experlinantal conflguration 1 s shown in Figure 5 . This measurement requires the jeneration of "short" optical pulses. "short" meanina times much less than the expected temporal resolution of the unit under test. The ohortest pulses available were 12-15 picoseconós and were generated by driving a spectra physics tye laser (using Rodamin 6G) with a continuous atrem of pulses from a pectra physics $\mathrm{Kr}^{+}$laser.

The cavity dumper for this dye laser needs tu be aynchionlzed in some way wlih readout system and the sweep for the etreak tube. Each pulse from the dye laser must or lginate at such a time that upon its arrival at the photocathode, the aweep will position the resulting trace on the plosphor. This is performed by upplying an external trigger to the cavity dumper drive units from a cujncidence bet.den the drive to the $\mathrm{Kr}^{+}$lager and a divided clock pulae. In this manner it is posible to investigato the characieristica of temporal "opreading" of the 12 psec: laser pulse oxcept for the lack of timing information on the otreak tube. Timing Inforination wais supplied by beam-spiltting and delaying the optical pulae from the dye laser. With accurate knowledge of this tirie delay, two pula will ppear at the phoaphor with the syacing between these pulaes corresponding to the knowin time delay. With tilis timlng information the width of each pulge can be related to $t$ ime. By appropriate "jeconuslution" the contilbution of the gtreah tube to the tomporal ranolution can be deteimined. As an ealimate of this resolution we subtract. In quajrature, tha known contributors to the obseryed pulse wicleh from the observed pulae width. The fundainental contributions ares

(1) (At) elreak -.- renponse of gtreak tuben

(2) (At) pulae -... finite width of lader pulne

(.) (At) rinot -. Elinte wlath of static imago 
Contribution (3) 18 a manifestation of the limit of the system to producing a finite extent image at the phosphor for an infinitesimal (spatial) input image. This width will translate to time, the two being celated by the aweep speed used.

Figure 6 displays these two pulses separated in time by 2.7 nanoseconds. A series of such measurements are made in order to complle statistics on the experimental precision. The output of the spectra-physics dye laser pulses was pertodically monitored using an auto-correlator in order to measure the width of the optical pulse. The resolution capabilitj of this auto-correlator is ql picosecond.

The probable limits of error for thnse pulse width measurements are calculated as approximately 2 picoseconds. Although it 18 belleved that the accuracy and precision of these measurements $1 \mathrm{~s}$ more than adequate $1 \mathrm{t}$ should be pointed out that care must be taken to isoiate and understand causes of potential pulse widening. One example of this 15 the possible variation of the temporal gcale as a function of position on the phcsphor. This is not atrictiy a spetial resolution problem but a geometric distortion and has resulted in grossly varying temporal resolution measurementa. A second probjem is the relationship between avallable optical pulges at a wavelength communsurate with the photocathode response. Optimaliy the sourse wavelength should be at or near the peak photorathode response so as to maximize signal to ratio of the measurement.

The extinction ratio is defined for tube with an extraction grid. It is the ratio of measured intensity at the phosphor for the extraction grid biased on and then off. The measirement 18 made by using either an EGSG 550 radiometer or a photomultipher. The extraction grid ia blased to a value whlch would prevent any photoelectrons fiom passing through the cathode to the phosphor. Due to the conflguzation a small but finite probability exists that Bome electrons will make it to the phosphor. This measurement 15 relatively routine and oimply yielding a single number of this ratio.

\section{Tube with internal CCD}

In the tubes described previously, the incident light from allt or an array of optical flbers is converted by the photocathode into a rlbbon of electrons within the tube. This electron otream is then swept across the output phosphor, ana converted to a rectangular visible light image. This is either lens or fiber optically coupled into an optical intensifier which can then output itg light image onto film or vidicon tube. These additional conversions of the output light again into electrons and bnck to light each add their own noise and distortions.

It is thus quite attractive to put device senoltive to a few electrons into the orlginal btreak tube envelope before any intermediate conversions bark into liqht. 2,3 One of the benefits of thls approach 18 tho geometrical certainty of position. Each element 18 precisely located within the tube and thus the only possibje geometric distortions arlse from the olectron optics within the otreak tube 1 toelf. There are gigniflcant problem areas, however. Penetration of the electrons into the approprlate charge gathering region wlthout effecting the transfer mechanism lo high on the list of potentlal problems. When the electrons impinge upon the shift registers and cutput amplifler of the CCD chip som damage is done. The nolse will increase. A good match must also be made to the size of the pixel in the CCD to this amallest resolution element of the treak tube. Finaliy as there is inherent gain in the CCD chip, and o finite caparity to the transfer mechanlem. aturation 18 a real problem at high light levels. We will descirbe a preliminary attempt at putting a Fairchild CCD imager into the output plane of a llamamateu streak tube.

The Fairchild CCD 221 devlce was prepared by the manufacturer without 1 to surface protective overlayer of 510 . Hamamutsu Corporation of Japan mounted the device in place of a phosphor in a atreak tube with about a $9 \mathrm{~mm}$ diameter photocatiode and no internal microchannel plate amplifler (Fig. 7). Unfortunately the tube bake out process ralsed the temperature of the $C C D$ above that of the manufucturer's recommendation and the latter was damaged. Ito nolse level was raibal signiflcantly. However, It was otlll operabie and allowed us to ovaluate the gystem within the limltations of the chip.

It was posible to couple sufficlent photons directly through the phutocathoric and the cential anode aperture to directly characterise the chlp with its responne to light. Then thn atreak tube rould be operated and uch characterlatics a dynamic range (1isa taken 2 ordurs of magnitude) and resojution (lese than $51 \mathrm{p} / \mathrm{mm}$ ) were determliled. Ihe meaguring techniques for these character. il uns - a well as for photocathode reoponse, time response, and opot ize was des.ribed above.

I'he accompanyini plot (Flg. B) dioplaylng amplitude measured at the CCD output ye NI) flter is tor explaining the apparont degradation of dynamic rallye. The basic philonophy was to loolate the effect of the pliotocathude on the syetem response. A lle, Ne laber was 
set up go as to pass through the ancde aperture and activate the sensitive CCD elements. The intensity was varied by calibrated neutral density filters. The camera output was digitized and anajyzed on an RCI image processing system. The vercical axis on the plot are just the digitized levels. No absolute intensity (i.e. watts/cm ${ }^{2}$ ) is inferrisd by these numbers. The laser beam was then offset from its original orientation and the photocathode blised (at was not in the previous test). The same sets of measurements were performed and recorded. This comparison indicates the dynamic range of the CCD itself is less than 100 and geverely imits the overall system dynamic range.

The remaining plots (Figs. 9 and 10) show a monitor picture and an intensity profile output from the streak tube when illuminating the photocathode with a bar chart resolution target. The line spacings were determined by comparison with a known line spacing pair. The measurements were performed with the streak tube in a "static" (not swept mode) and indicate a $258 \mathrm{MTF}$ for $1.9 \mathrm{lp} / \mathrm{mm}$. It is believed that these measurements are affected by the extremely poor signal to noise ratio, but nonetheless indicate the as 18 " performance.

The principle of placing a solid state imaging device within a tube is viable. The long term lifetime of the S-20 photocathode has not degrated from the presence of the imaging device. However in altu photocathode processing is apparently incompatible with the preservation of the CCD chip in its nominal otate and further experiments in this mode await a remotely processed photocathode.

\section{References}

1. Majumdar, S., Dynamic Range of Picosecond Streak Camerag, Proceadings of 12 th International Congress on High Speed Photography, 1976, A-5.

2. Savoye, E. D., et al., Design and Performunce of a CCD-Streak Tube, SPIE Vol. 203. $1979,59,65$.

3. Cheng, J. C., et al. Intenglfled CCD Readout System for Ultrafast Streak Cameras. J. App1. Phys., Vol. 49, 5421-5426. 


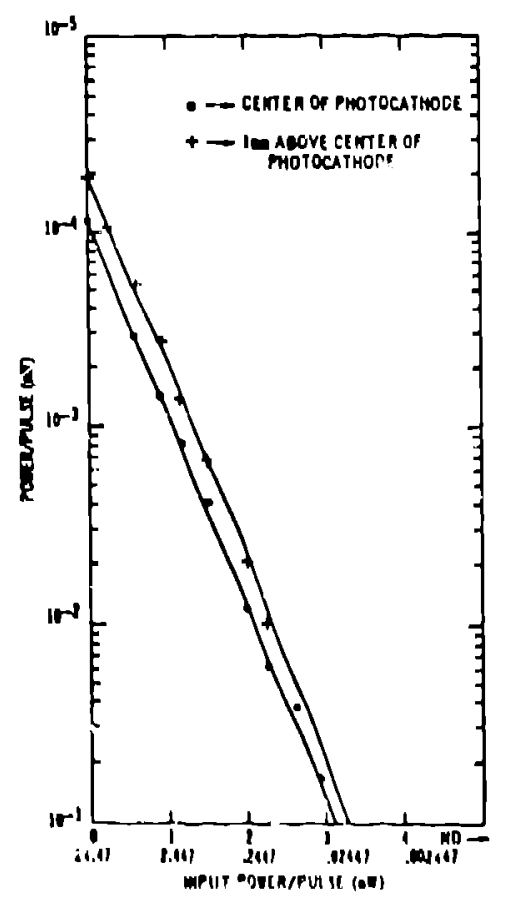

Fis 1 


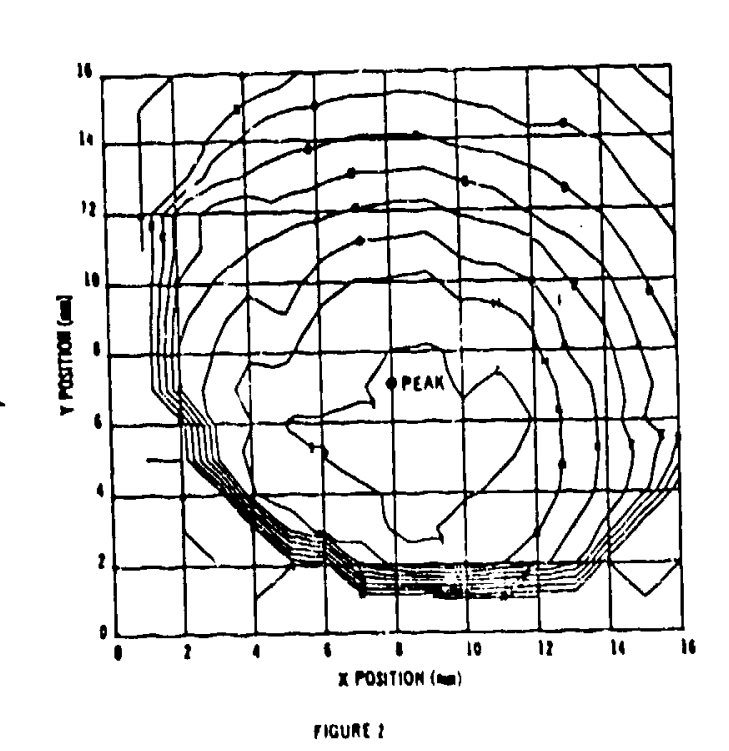




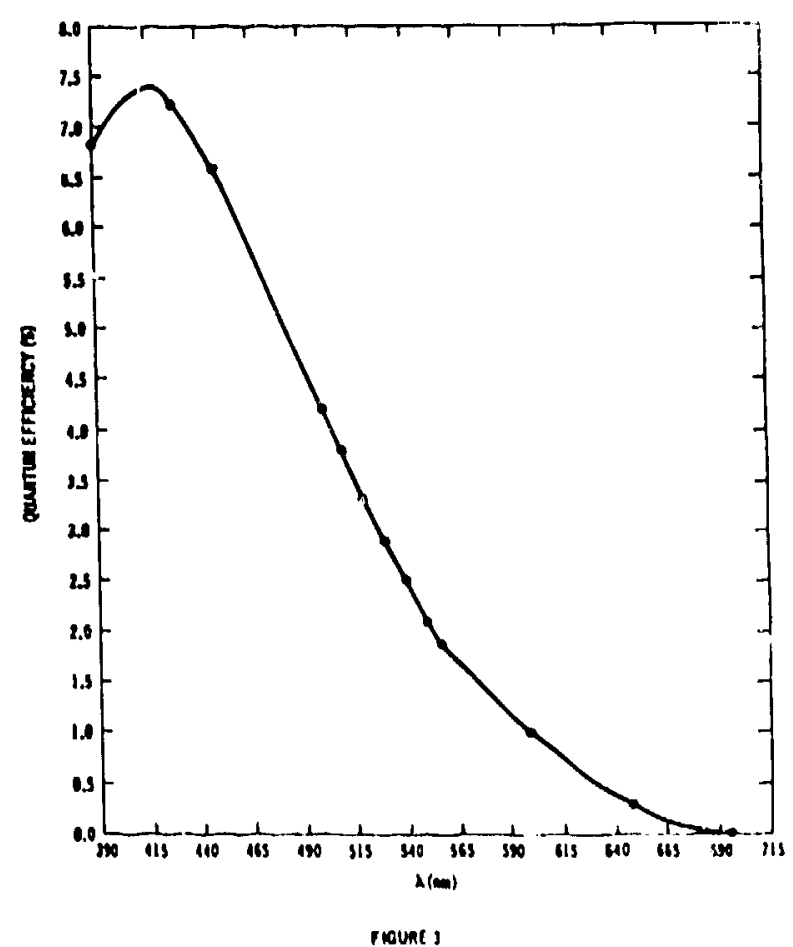


$2 i 4$

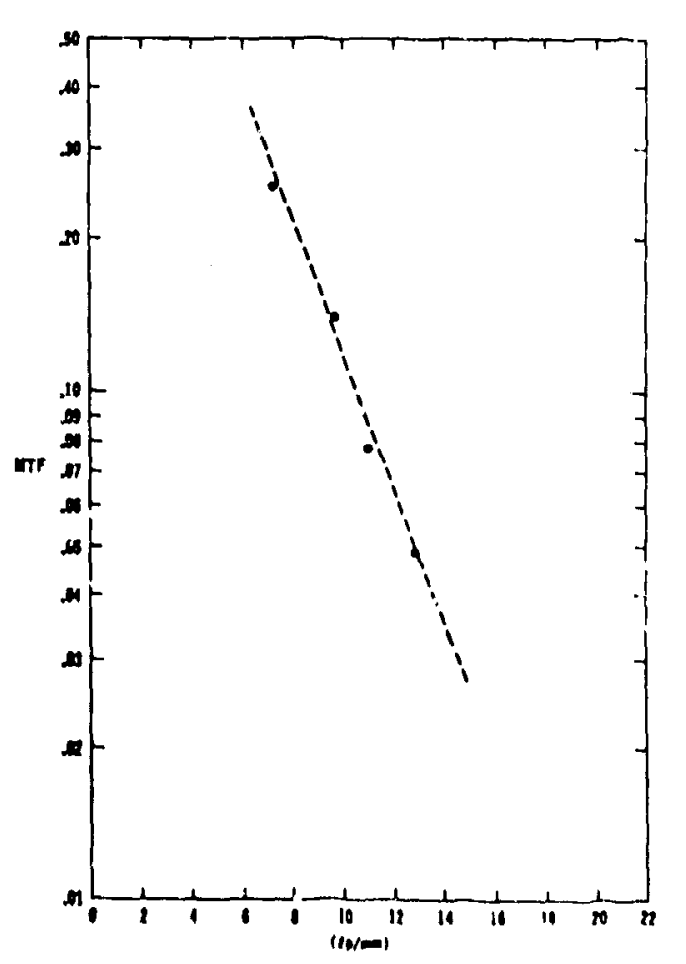




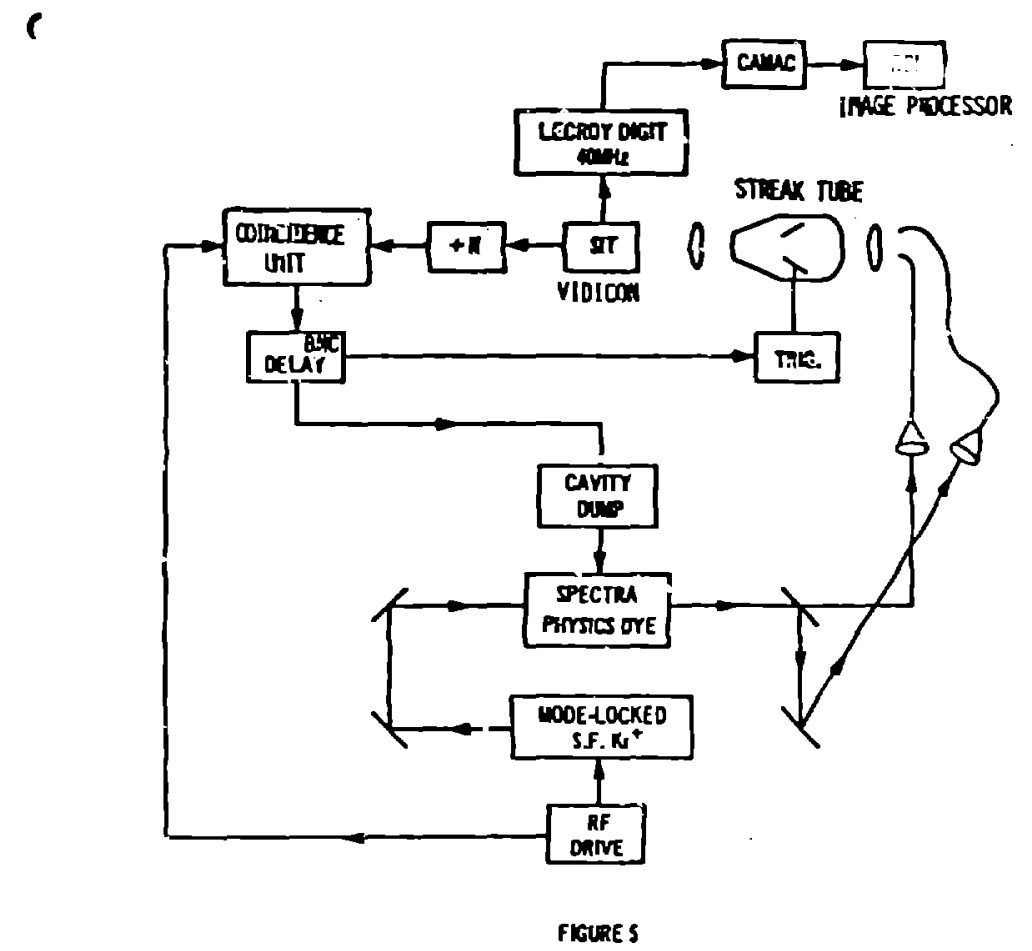




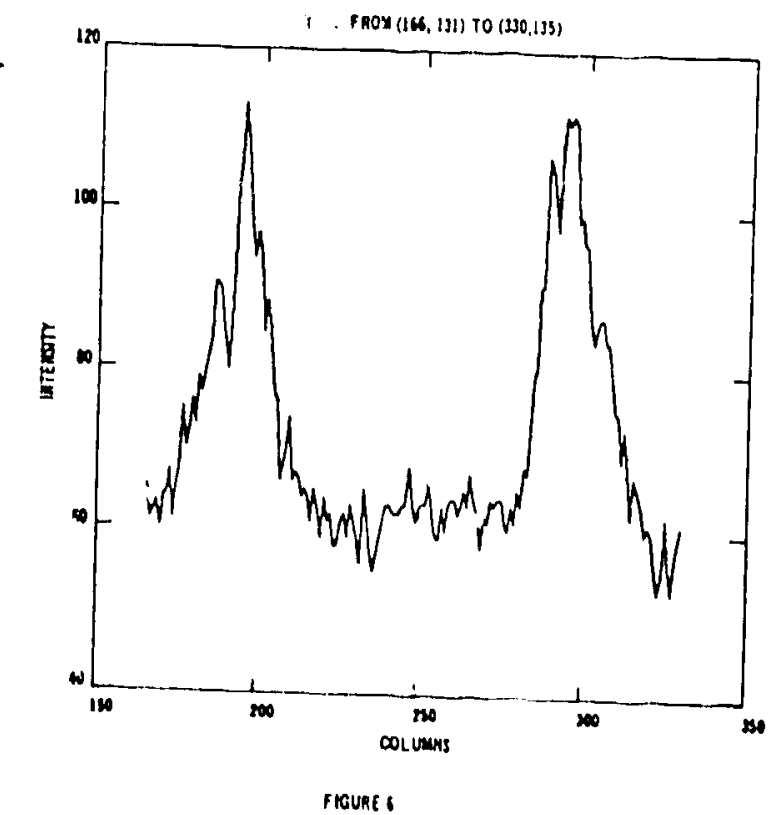




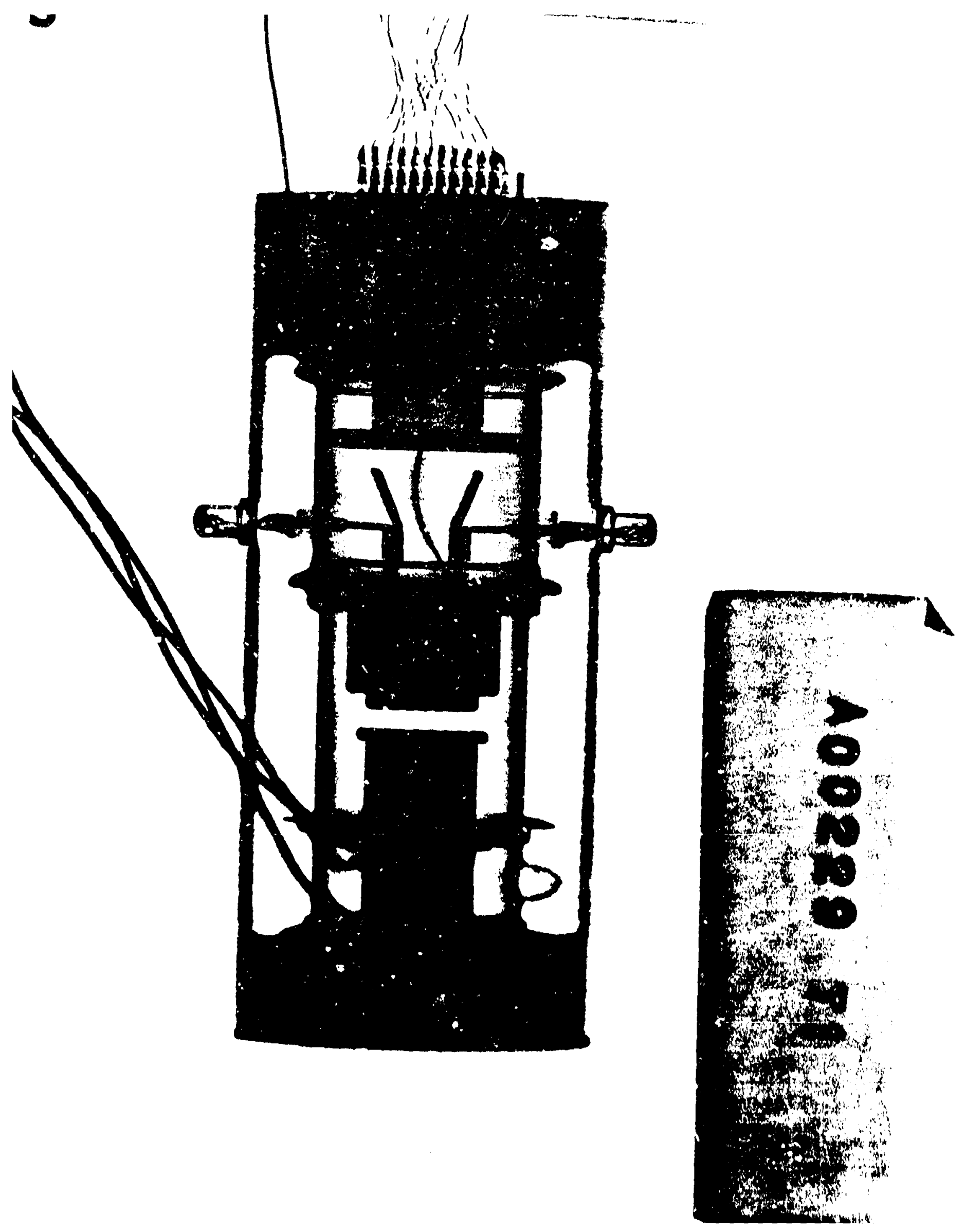


figs

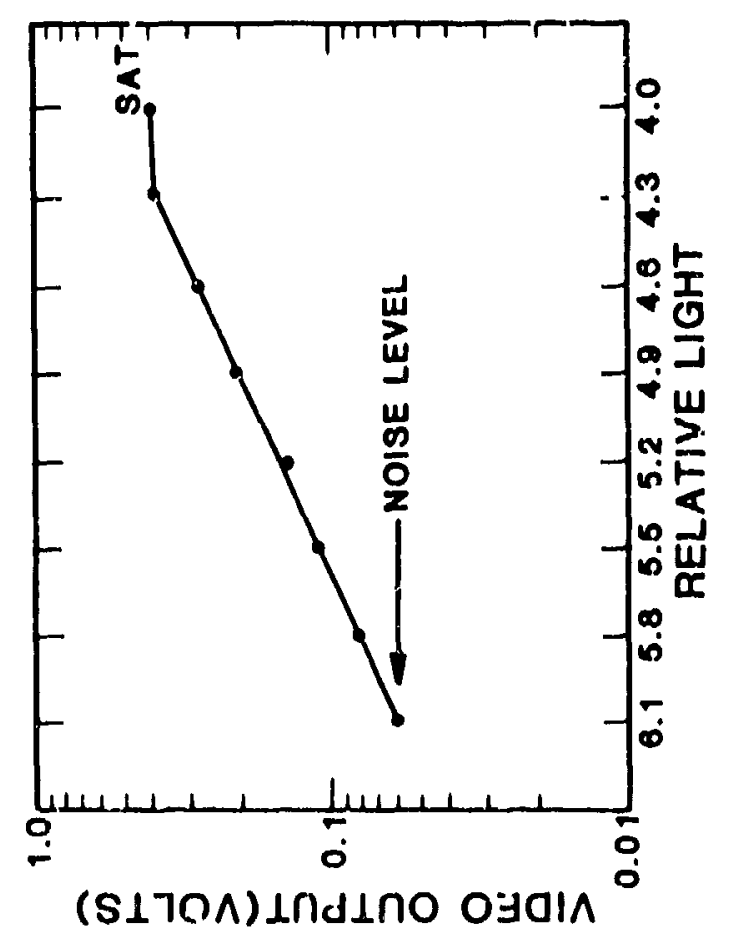




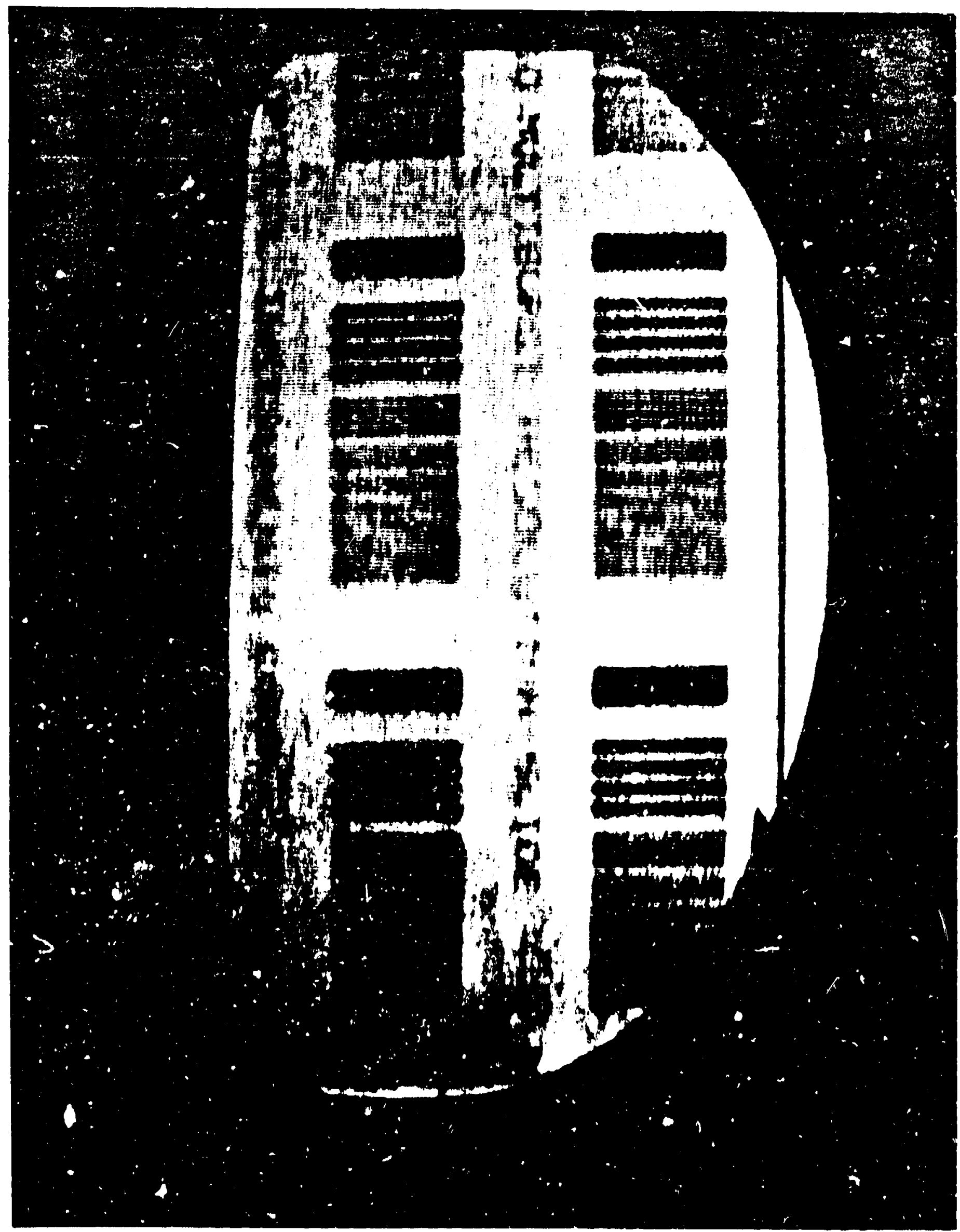




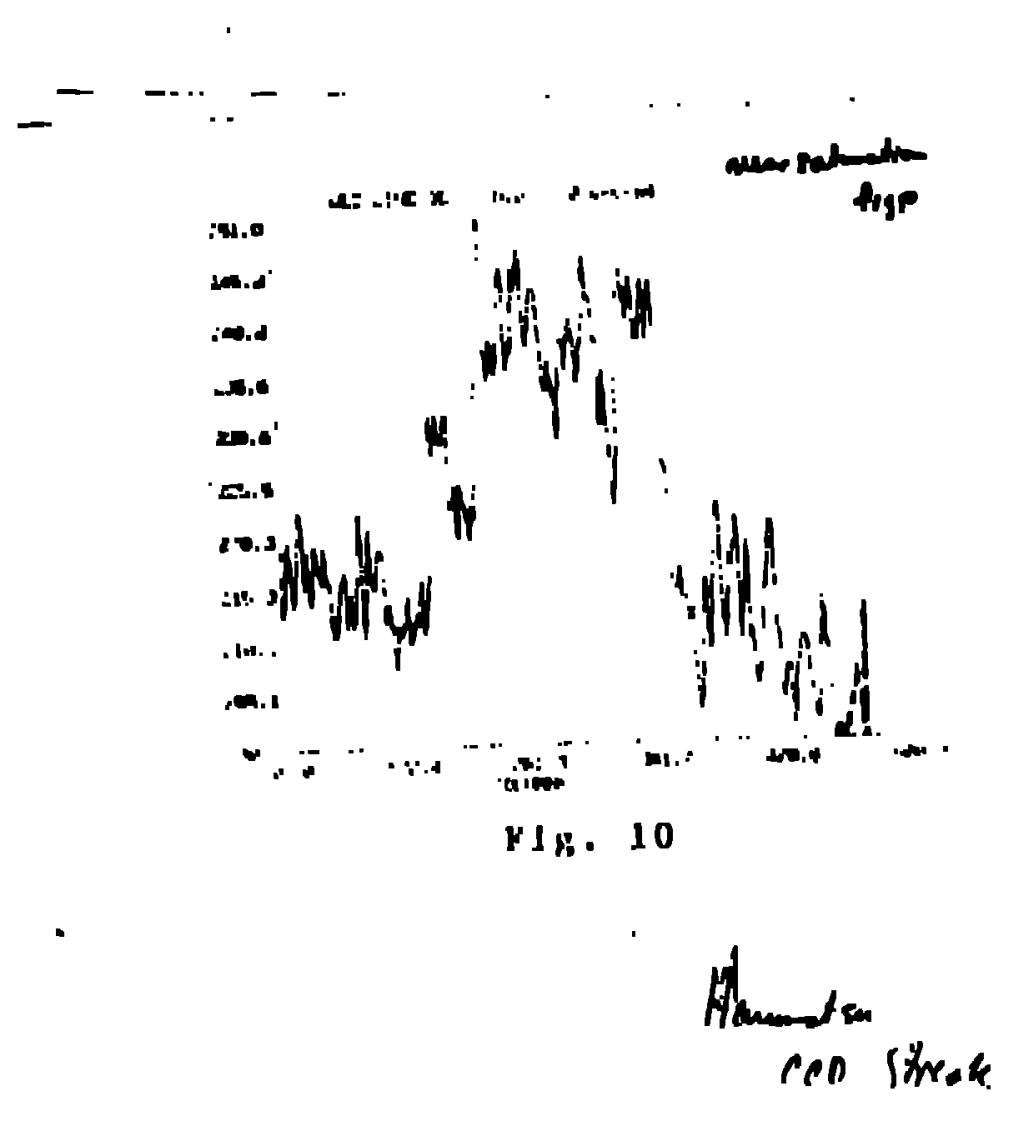

